\title{
LC-(TIC/EIC)-MS as Tool in the Analysis of Diastereomeric 3,12-aza-analogues of Deoxycholic Acid
}

\author{
Dieter Verzele ${ }^{a}$, Jan L. Goeman ${ }^{b}$ and Annemieke Madder ${ }^{a, *}$ \\ Ghent University, Department of Organic Chemistry, ${ }^{a}$ Laboratory for Organic and Biomimetic \\ Chemistry; ${ }^{b}$ Laboratory for Organic and Bioorganic Synthesis; \\ Krijgslaan 281 (S4), B-9000 Ghent, Belgium \\ E-mail: annemieke.madder@Ugent.be
}

Dedicated to Professor Alain Krief on the occasion of his $65^{\text {th }}$ birthday

\begin{abstract}
The non-conventional Total Ion Current (TIC) detection and corresponding Extracted Ion Current (EIC) chromatogram in LC-MS measurements, have been used for quantitative analysis of reactions involving UV-inactive aza-analogues of deoxycholic acid. LC-(TIC/EIC)-MS experiments allowed for the accurate determination of diastereomeric and overall purity during the development of a new synthetic route for an orthogonally protected dipodal steroid scaffold with defined stereochemistry. Moreover, this technique facilitated adequate monitoring of further scaffold derivatization on solid support. The described methodology offers an attractive solution in cases where conventional HPLC analysis with UV detection fails.
\end{abstract}

Keywords: LC-MS, TIC/EIC detection, steroids, dipodal scaffold, Alloc deprotection

\section{Introduction}

In our quest for new synthetic models of naturally occurring proteins we became interested in the design of dipodal peptidosteroid receptors, based on the attachment of short minimal recognition peptides to steroid scaffold $\mathbf{1}$, derived from deoxycholic acid $(3 \alpha, 12 \alpha$-dihydroxy-5 $\beta$-cholan-24oic acid) (Figure 1). The defined geometrical properties and the orthogonal protection of the attachment points are the main features of this scaffold, permitting the design of not only homo-, but also heterodimers with a specific pre-organization. Furthermore, the C24 carboxylic acid provides a natural link for immobilization on a solid support. 


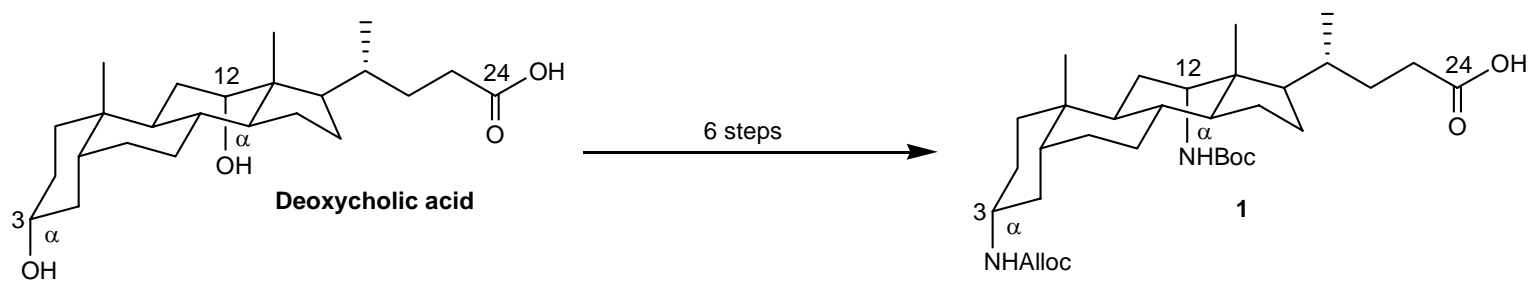

Figure 1. Deoxycholic acid and dipodal steroid scaffold 1.

To efficiently obtain sufficient quantities of scaffold material in a short time period, we conceived a new synthetic route, applying a very straightforward strategy. ${ }^{1}$ Whereas previously published routes for similar scaffolds require a large number of synthetic steps (usually $>10$ ), ${ }^{2}$ we were able to significantly limit the number of steps to only six. In contrast to the commonly used sequential derivatization of the hydroxyl functions, necessary to guarantee the correct stereochemistry and differentiation of the different positions, we proceeded via the simultaneous transformation of these functions to the corresponding diamine. Further differentiation was based on the difference in steric impediment of the $\mathrm{C} 3$ and $\mathrm{C} 12$ position in (deoxy)cholic acid (derivatives). ${ }^{3}$

During the development of this short synthetic route we faced various challenges, especially concerning the purification and analysis of the formed diastereomers. We here report in detail on the large-scale, chromatographic separation of these diastereomers and the combination of analytical techniques necessary for the unambiguous determination of purity and identity of the formed/isolated compounds. In particular the on-line use of non-conventional Total Ion Current detection during reversed-phase HPLC analysis and the resulting Extracted Ion Current chromatogram (TIC/EIC) proved invaluable in this context.

\section{Results and Discussion}

Scheme 1 depicts the key steps of the optimized synthetic route, which also represent the most challenging ones. In order to significantly lower the amount of synthetic steps, we decided to directly transform deoxycholic acid via the dioximo carboxylic acid 2 into the corresponding diamine $3(\mathbf{a}+\mathbf{b})$, applying conditions previously reported by Burrows et al. for reduction of analogous dioximo derivatives with $\mathrm{C} 24$ alcohol. ${ }^{4}$ A one-pot esterification procedure was necessary to obtain the compound as pure diamino n-propyl ester. Being less polar, this compound proved much easier to isolate from the reaction mixture by conventional liquid extraction than its charged diamino carboxylic acid analogue. ${ }^{1}$ In this way it is possible to conserve the carboxylic acid (protected as an ester) without the need for additional reduction or protection steps. Conservation of the $\mathrm{C} 24$ carboxylic acid moiety allows for later immobilization on solid support via a stable amide bond, circumventing possible problems associated with products immobilized through a more labile ester bond via the $\mathrm{C} 24$ alcohol. 


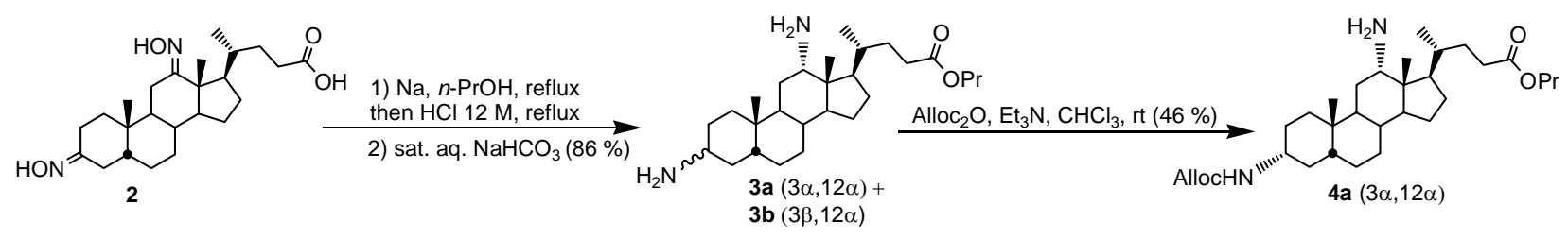

Scheme 1. Key steps of the short synthetic route towards $\mathbf{4 a}{ }^{1}$

Thin Layer Chromatography (TLC) clearly showed the formation of products with similar Rf values $\left(0.18 ; 0.27 ; 0.35 ; 0.43\right.$ in EtOAc: $\left.\mathrm{MeOH}: \mathrm{NH}_{4} \mathrm{OH}_{\mathrm{aq}} 9: 1: 1\right)$, assumed to be diastereomers formed during the reduction. The major spot $(\mathrm{Rf}=0.27)$ could be isolated by flash chromatography. Separation is efficient provided conditions are rigorously controlled. Flash chromatography using Merck grade 9385 silica gel (60 Angström, 230-400 mesh) was necessary to achieve succesful and reproducible separation. Elution in this large-scale separation should proceed with a somewhat atypical EtOAc: $\mathrm{MeOH}: \mathrm{NH}_{4} \mathrm{OH}_{\mathrm{aq}}$ 28:3:1 mixture. In the work published by Burrows et al. formation/isolation of diastereomers was not mentioned and only the isolation of pure $3 \alpha, 12 \alpha$-diamino-5 $\beta$-cholan-24-ol in $62 \%$ yield from reduction of 3,12dioximo-5 $\beta$-cholan-24-ol was reported. ${ }^{4}$

Until now, published procedures frequently use ${ }^{1} \mathrm{H}$ NMR to judge the diastereomeric purity of similar compounds. ${ }^{2 \mathrm{~b}-\mathrm{c}, 4,5}$ The $\alpha$ or $\beta$ orientation of the proton adjacent to the electron withdrawing $\mathrm{N}$-atom results in a specific chemical shift and coupling pattern. In our hands ${ }^{1} \mathrm{H}$ NMR spectroscopy alone proved insufficient to fully assess the diastereomeric purity. The most intense and clearly identifiable signals of the $\mathrm{C} 3-\mathrm{H}$ and $\mathrm{C} 12-\mathrm{H}$ were consistent with the $3 \beta \mathrm{H}, 12 \beta \mathrm{H}$ geometry, thus the $3 \alpha \mathrm{N}, 12 \alpha \mathrm{N}$ products being the main compounds. Chemical shifts $(\delta)$ proved very similar to literature data for both the $3 \beta$ and $12 \beta$ proton and integrations were consistent. Moreover the shape of both peaks was consistent with coupling patterns, since $3 \beta \mathrm{H}$ is broadened due to large axial-axial couplings, in contrast to $12 \beta \mathrm{H}$. Table 1 illustrates the satisfying agreement of experimental with literature data. ${ }^{4}$

Table 1. ${ }^{1} \mathrm{H}$ NMR $\delta$ (in ppm) comparison for compound 3a with literature

\begin{tabular}{c|cccc}
\hline & Literature $^{4}$ \\
$3 \beta \mathrm{H}$ \\
$12 \beta \mathrm{H}$
\end{tabular}


However no reliable, reproducible and clearly identifiable signal for the corresponding $\alpha \mathrm{H}-$ $(\beta \mathrm{N})$-isomers could be located. Furthermore, there was no clear difference between spectra of crude extract and purified fractions.

Therefore, in order to accurately judge the diastereomeric purity of the compounds, we had to rely on HPLC based methods. The complete absence of UV-activity above $214 \mathrm{~nm}$ complicated the analysis and no clear peaks could be observed in the chromatograms. However, the hyphenation of reversed-phase HPLC to an Electrospray Ionization Mass Spectrometer (LC-MS) and the resulting Total Ion Current (TIC) chromatogram provided the necessary information. Especially the corresponding Extracted Ion Current (EIC) chromatogram proved invaluable in judging the diastereomeric ratio of the compounds. In the EIC chromatogram only the ions of a particular molecular mass are taken into account, thus (mathematically) extracting specific information (EIC) out of the crude data (TIC). This methodology is in our case justified since the diastereomers can be assumed to ionize equally. In order to reduce tailing of the amines the addition of $0.1 \%$ formic acid to the eluent was necessary to obtain sharp, separated signals.

The data extraction principle using EIC is clearly illustrated in Figure 2. The TIC chromatogram A, obtained from the reduction/esterification reaction mixture (Scheme 1, conversion of $\mathbf{2}$ to $\mathbf{3 a}+\mathbf{3 b}$ ), looks quite messy and interpretation is therefore difficult. Whereas this chromatogram gives no clear information, the corresponding EIC chromatogram B proves very diagnostic in identifying the formation of four diastereomers, as previously suggested by TLC results.

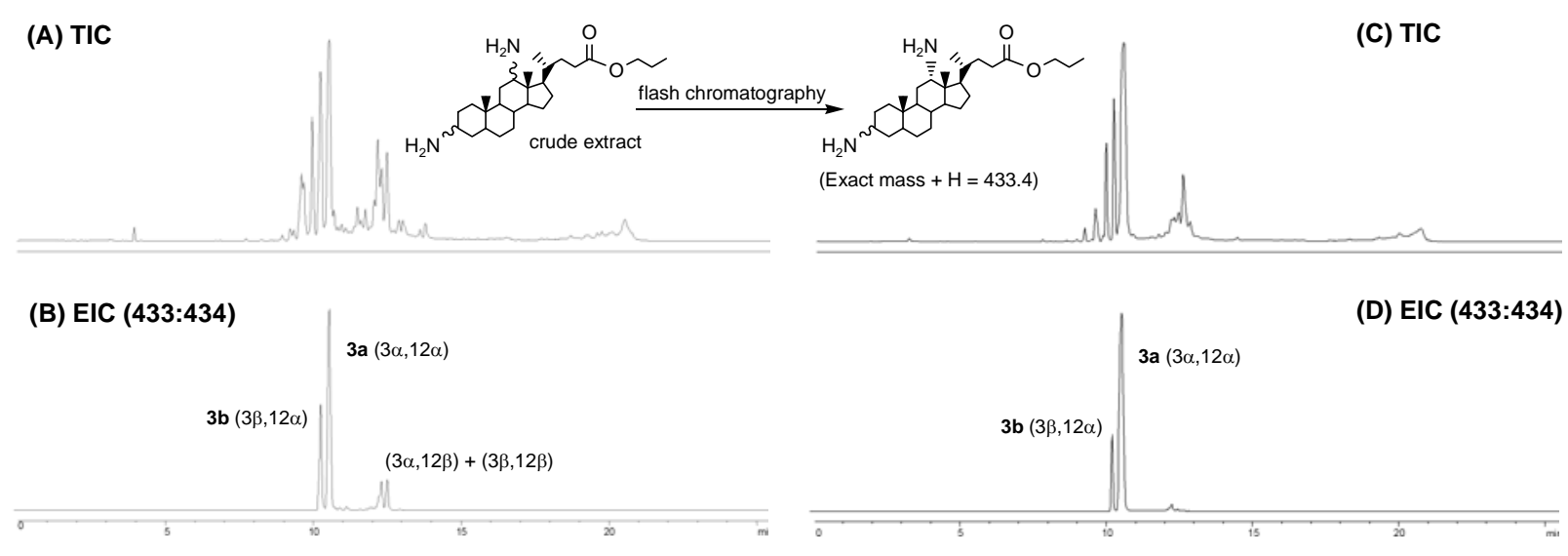

Figure 2. (A) TIC chromatogram of crude reaction extract; (B) Corresponding EIC chromatogram; (C) TIC chromatogram of chromatographically purified mixture; (D) Corresponding EIC chromatogram (target molecular weight range is shown between brackets).

Results from literature indicated the $3 \alpha, 3 \beta / 12 \alpha$-isomers being expected as major compounds and the $3 \alpha, 3 \beta / 12 \beta$-isomers as minor compounds. ${ }^{2 \mathrm{~b}-\mathrm{c}, 4,5 \mathrm{a}-\mathrm{b}, 5 \mathrm{~d}}$ Surprisingly EIC chromatogram D, corresponding to TIC chromatogram $\mathrm{C}$, clearly shows that the pure, main spot on TLC still consists of the two major compounds, again believed to be the $3 \beta, 12 \alpha$ (3b) and $3 \alpha, 12 \alpha$ (3a) 
isomers (diastereomeric ratio 15:85). Separation of the undesired isomer at this stage proved very labour-intensive and we therefore decided to proceed with $\mathrm{C} 3$ protection and separate at a later stage.

After introduction of the Allyloxycarbonyl (Alloc) protecting group ${ }^{6}$ (Scheme 1, conversion of $\mathbf{3 a}+\mathbf{3 b}$ to $\mathbf{4 a}$ ), the product mixture consequently consisted of the two $\mathrm{C} 3$-monoprotected diastereomers 4a $+\mathbf{4 b}$ (Figure 3, EIC chromatogram A). In contrast to the diamino $n$-propyl ester mixture $\mathbf{3 a}+\mathbf{3} \mathbf{b}$, the monoprotected derivatives could be completely separated chromatographically, as shown in Figure 3, TIC chromatogram B and corresponding EIC chromatogram $\mathrm{C}$. From these chromatograms it could be concluded that compound 4a was obtained in a satisfying overall purity (TIC chromatogram B) and an excellent diastereomeric purity (EIC chromatogram $\mathrm{C}$ ), considering only one flash chromatographic purification is required. Furthermore, after a verification step (see experimental section for details) involving the removal of the C3-NHAlloc protecting group from compound 4a, LC-(TIC/EIC)-MS (not shown) clearly confirmed the absence of the minor diamino isomer $\mathbf{3 b}$. Flash chromatographic conditions should again be strictly controlled. Elution with $\mathrm{CH}_{2} \mathrm{Cl}_{2}: \mathrm{MeOH}$ 98:2, again using Merck grade 9385 silica gel are prerequisites for successful separation.

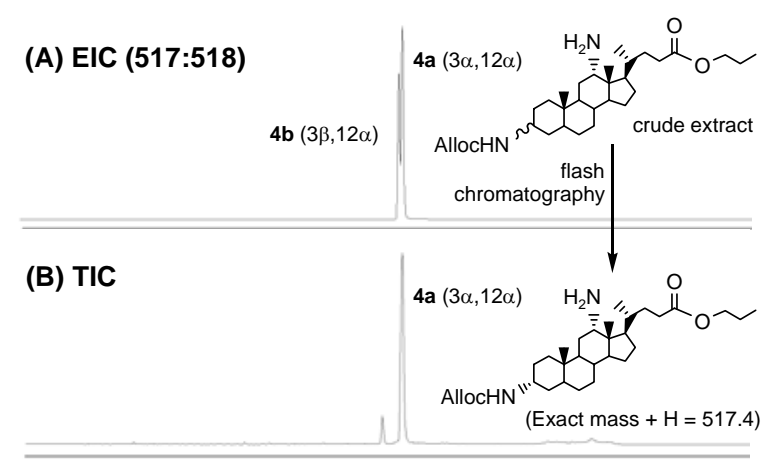

(C) EIC (517:518)

Figure 3. (A) EIC chromatogram of crude extract; (B) TIC chromatogram of purified 4a; (C) Corresponding EIC chromatogram (target molecular weight range is shown between brackets).

In this way the desired $\mathrm{C} 3 \alpha-\mathrm{NHAlloc}, \mathrm{C} 12 \alpha-\mathrm{NH}_{2}$ diastereomer 4a could be isolated and characterized. Although comparison of ${ }^{1} \mathrm{H}$ NMR spectra with literature data ${ }^{2 \mathrm{c}, 4 \mathrm{a}, 5 \mathrm{a}-\mathrm{d}}$ confirm the correct identity of the major isomer, LC-(TIC/EIC)-MS experiments were clearly necessary to judge the overall and diastereomeric purity of this compound.

The LC-(TIC/EIC)-MS technique described above proved also very helpful in monitoring further on-bead scaffold derivatization. The development of analytical tools for the accurate 
monitoring of reactions on solid support is an important, progressing field in contemporary research. Analysis often has to rely on minute quantities obtained from cleavage of a single bead and sensitive methods based on mass spectrometry are therefore necessary for quality control of solid phase (library) synthesis. In the process of generating dipodal steroidal peptidomimetics on solid support, some preliminary experiments concerning the deprotection of the scaffold on solid support were performed. In one particular case, we tested the sequential deprotection of the C12NHBoc group and C3-NHAlloc group of the scaffold. The use of a photocleavable linker ${ }^{7}$ (Figure 4) makes cleavage of small compound quantities from the support very easy, providing samples immediately ready for further HPLC and MS based analysis. ${ }^{8}$

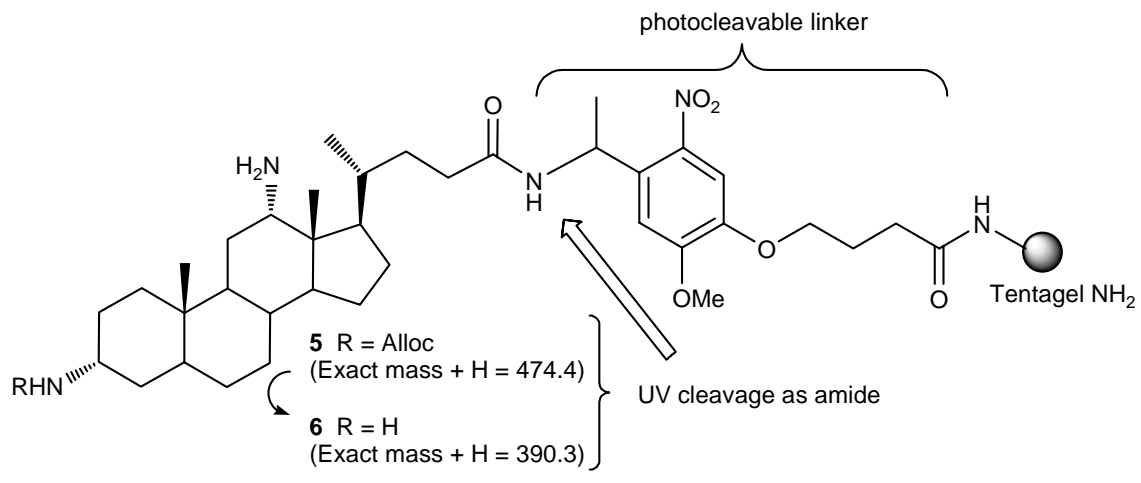

Figure 4. Alloc deprotection of solid supported construct 5.

Although generally used as protecting group in a variety of applications, the Pd-catalyzed Alloc deprotection is often a challenging reaction. Next to incomplete, sluggish reactions, the Nallylation of the free amino group by the liberated allyl cation is a considerable side reaction. ${ }^{6,9}$ Until recently, we usually followed reaction progress by photolytic cleavage of a few beads and immediate analysis of the obtained reaction mixture by $\mathrm{ESI}^{+}-\mathrm{MS}$. From these ESI ${ }^{+}$-MS spectra (Figure 5), some preliminary conclusions can be drawn.
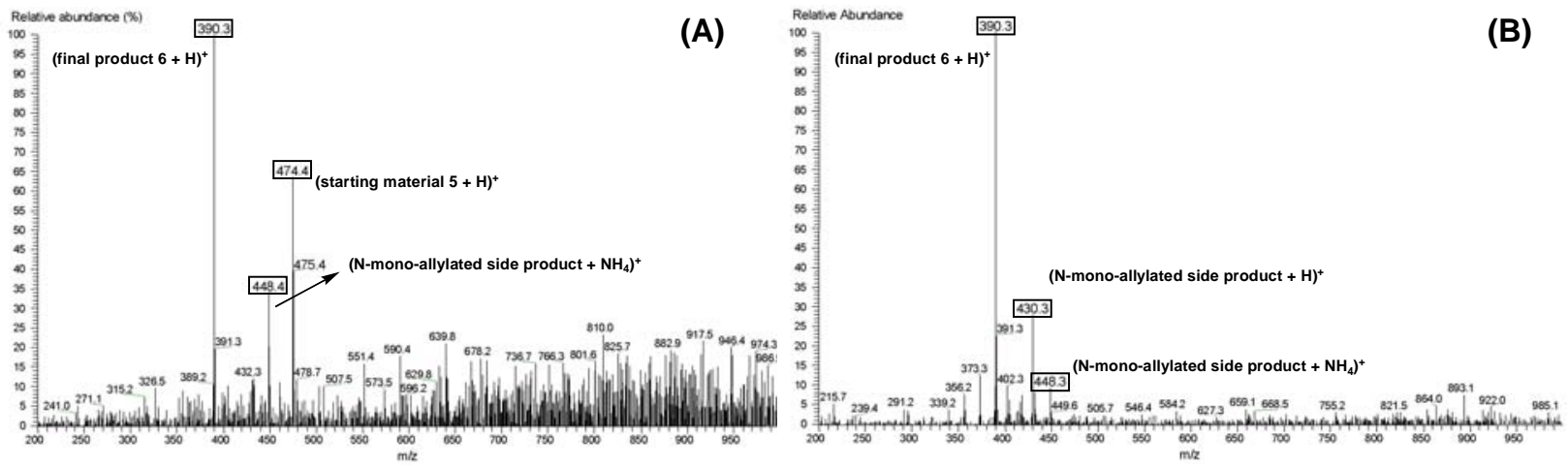

Figure 5. $\mathrm{ESI}^{+}$-MS spectra of Alloc deprotection (A) after second treatment with $\mathrm{Pd}\left(\mathrm{PPh}_{3}\right)_{4} /$ $\mathrm{Bu}_{3} \mathrm{SnH} /$ morpholine; (B) after treatment with $\mathrm{Pd}\left(\mathrm{PPh}_{3}\right)_{4} /$ anilinium $p$-toluenesulfinate. 
The use of $\mathrm{Pd}\left(\mathrm{PPh}_{3}\right)_{4} / \mathrm{Bu}_{3} \mathrm{SnH}$ with morpholine for 22 hours didn't result in quantitative removal of the Alloc group, even after repeating the reaction. As shown in spectrum A, the sample still consisted of a mixture of Alloc protected starting material $\mathbf{5}$ and deprotected final product 6. Moreover, a significant signal of $\mathrm{N}$-(mono)-allylated side product (Exact mass $+\mathrm{H}=$ 430.4; Exact mass $+\mathrm{NH}_{4}{ }^{+}=447.4$ ) was detected. In contrast, the ESI ${ }^{+}$-MS spectrum after the use of $\mathrm{Pd}\left(\mathrm{PPh}_{3}\right)_{4}$ with anilinium $p$-toluenesulfinate ${ }^{9 \mathrm{~b}, 10}$ for only 2 hours showed almost complete deprotection, with no significant increase of $\mathrm{N}$-(mono)-allylated side product (spectrum B). The ionization of the compounds being unpredictable and unreproducible, it was difficult to draw more quantitative conclusions about the progress of the reaction and the extent of the side reactions.

Using the described LC-(TIC/EIC)-MS methodology, more quantitative information was obtained and the reaction could be monitored more adequately (Figure 6).

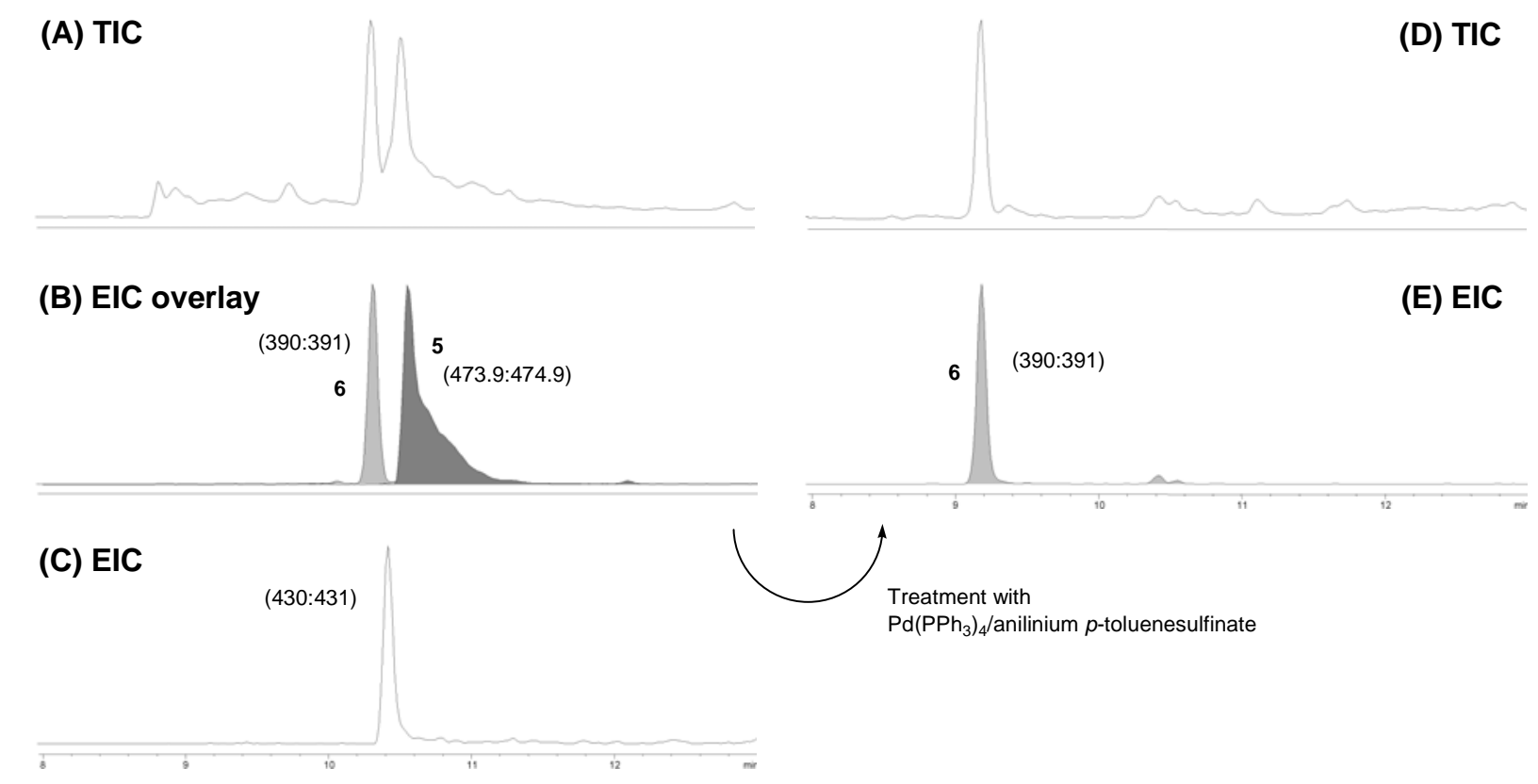

Figure 6. LC-(TIC/EIC)-MS of Alloc deprotection: (A) TIC chromatogram after second treatment with $\mathrm{Pd}\left(\mathrm{PPh}_{3}\right)_{4} / \mathrm{Bu}_{3} \mathrm{SnH} /$ morpholine; (B) Superimposed EIC chromatograms of Alloc protected starting material 5 and deprotected final compound 6; (C) EIC chromatogram of N(mono)-allylated side product; (D) TIC chromatogram after treatment with $\mathrm{Pd}\left(\mathrm{PPh}_{3}\right)_{4}$ /anilinium p-toluenesulfinate; (E) EIC chromatogram of deprotected final compound 6 (target molecular weight range is shown between brackets).

The two peaks obtained in TIC chromatogram A after twice applying $\mathrm{Pd}\left(\mathrm{PPh}_{3}\right)_{4} / \mathrm{Bu}_{3} \mathrm{SnH} /$ morpholine were identified as starting material and final product by the corresponding EIC chromatograms, as shown in B, where EIC chromatograms of $\mathbf{5}$ and $\mathbf{6}$ are 
superimposed. The N-(mono)-allylated side product can be found in between starting material 5 and deprotected compound $\mathbf{6}$ as derived form EIC chromatogram C.

Results obtained after treatment with $\mathrm{Pd}\left(\mathrm{PPh}_{3}\right)_{4} /$ anilinium $p$-toluenesulfinate clearly showed the disappearance of starting material (TIC chromatogram D and EIC chromatogram E). Moreover, from TIC chromatogram D it could be concluded that only a negligible amount of N(mono)-allylated side product was formed. These results illustrate the usefulness of LC(TIC/EIC)-MS for the more accurate monitoring of reactions on solid support and made a significant contribution to the optimization of the Alloc deprotection.

\section{Conclusions}

In conclusion, we have demonstrated that the use of the TIC/EIC technique in LC-MS allows for a clear assessment of diastereomeric purity of UV-inactive aza-analogues of deoxycholic acid. To our knowledge, this is the first report on the use of this method in a steroid context. LC(TIC/EIC)-MS provided valuable data supplementary to other analytical methods such as ${ }^{1} \mathrm{H}$ NMR and ESI-MS. Both the development of a diastereomerically pure dipodal steroid scaffold for combinatorial chemistry and the adequate monitoring of further scaffold derivatization on solid support were greatly facilitated by this technique. This method could be generally interesting for detailed HPLC analysis of reaction mixtures when working with compounds of low UV-activity.

\section{Experimental Section}

General information. All reagents were obtained either from Aldrich or ACROS Organics and were used without prior purification. Reactions were performed under argon atmosphere using HPLC grade solvents (obtained from Sigma-Aldrich or Fisher Scientific). Optical rotations were recorded on a Perkin-Elmer 241 polarimeter at room temperature. Analytical TLC was carried out on glass plates precoated with silica gel (Macherey Nagel, 60F254, $0.25 \mathrm{~mm}$ ). Compounds were visualized with phosphomolybdic acid (PMA), $\mathrm{KMnO}_{4}$, ninhydrin (2,2-dihydroxy-1,3indanedione) or chloranil (tetrachloro-1,4-benzoquinone, $2 \%$ solution in DMF). Due to large differences in polarity between most starting materials and reaction products, two different eluent systems were used to follow most reactions on TLC. Flash chromatography was performed on Kieselgel Merck Typ 9385 230-400 mesh, 60 Angström.

NMR spectra were recorded at room temperature on a Bruker Avance-500 spectrometer at 500 $\mathrm{MHz}$ for ${ }^{1} \mathrm{H} \mathrm{NMR}$ and $125 \mathrm{MHz}$ for ${ }^{13} \mathrm{C}$ spectra. $\mathrm{CDCl}_{3}$ (99.8 atom \% D) was obtained from Aldrich. Chemical shifts ( $\delta$ units) are expressed in parts per million (ppm) relative to tetramethylsilane (TMS) and the internal solvent peak was used for calibration. When peak multiplicities are reported, the following abbreviations are used: s, singlet; $d$, doublet; $t$, triplet; 
m, multiplet; br, broad. Coupling constants ( $J$ values) are expressed in Hertz $(\mathrm{Hz})$. The Attached Proton Test (APT) technique was used to assign ${ }^{13} \mathrm{C}$ peaks $\left(\mathrm{C}, \mathrm{CH}, \mathrm{CH}_{2}, \mathrm{CH}_{3}\right)$. Assignment was aided by comparison with literature values for similar compounds. ${ }^{2 \mathrm{~d}, 4,11}$ Infrared spectra were recorded on a Perkin-Elmer 1600 Series FTIR spectrometer. Bands were quoted in $\mathrm{cm}^{-1}$ and the following abbreviations are used: w, weak; m, medium; s, strong; br, broad. Only the diagnostic signals are listed.

ESI-MS spectra were acquired on a quadrupole ion trap LC mass spectrometer (Thermo Finnigan MAT LCQ mass spectrometer) equipped with electrospray ionization. HR-MS values were measured on a Thermo Finnigan MAT95XP-Trap mass spectrometer. Reversed-phase LCMS was performed on an Agilent 1100 series HPLC, using a Phenomenex Luna C18 (2) (250 $\mathrm{mm} \times 4.6 \mathrm{~mm}$ ) column hyphenated to an Agilent ESI-single quadrupole MS detector type VL. The following gradient elution was applied:

\begin{tabular}{|l|l|l|l|l|l|l|}
\hline Time (min) & 0 & 2 & 17 & 22 & 23 & 26 \\
\hline $\begin{array}{l}\text { A (\%): } \mathbf{H}_{2} \mathbf{O}+\mathbf{0 . 1} \% \\
\text { HCOOH }\end{array}$ & 100 & 100 & 0 & 0 & 100 & 100 \\
\hline B (\%): $\mathbf{C H}_{3} \mathbf{C N}$ & 0 & 0 & 100 & 100 & 0 & 0 \\
\hline
\end{tabular}

Preparation of $3 \alpha, \beta$-diastereomeric mixture of $n$-propyl 3,12 $\alpha$-diamino-5 $\beta$-cholan-24-oate (3a + 3b). Dioximo carboxylic acid 2 (17.04 g, $40.71 \mathrm{mmol})$ was suspended in $n$-PrOH (3.5 L) and heated at reflux under argon. Sodium (56.44 g, $2.46 \mathrm{~mol}, 60.3 \mathrm{eq})$ was carefully added portionwise over a period of $3 \mathrm{~h}$. After addition of the last piece of sodium the reaction was heated at reflux overnight to ensure complete reaction of the sodium before quenching.

TLC indicated the complete consumption of starting material (acetone: $\mathrm{MeOH}$ 7:3 + trace HOAc; chloranil). A $12 \mathrm{M} \mathrm{HCl}$ aqueous solution $(210 \mathrm{~mL})$ was added very slowly to the refluxing mixture, leading to the immediate precipitation of $\mathrm{NaCl} .10 \mathrm{~mL}$ of a $12 \mathrm{M} \mathrm{HCl}$ aqueous solution was further added and the suspension was heated at reflux overnight $(\mathrm{pH}=1-2)$.

TLC showed complete conversion (EtOAc:MeOH: $\mathrm{NH}_{4} \mathrm{OH}$ 28.0-30.0\% aq 9:1:1; chloranil or $\mathrm{KMnO}_{4}$ ), indicating 4 diastereomers. The mixture was cooled to room temperature and the solvent was co-evaporated with toluene. The off-white residue was transferred to a separation funnel with $\mathrm{CHCl}_{3}$ and a saturated $\mathrm{NaHCO}_{3}$ aqueous solution was added $(\sim 1 \mathrm{~L}$ aqueous/ 1 L $\mathrm{CHCl}_{3}$ ). The phases were separated and the $\mathrm{H}_{2} \mathrm{O}$ was further extracted with two portions of $\mathrm{CHCl}_{3}$ (700 and $300 \mathrm{~mL}$ ). The organic phase was partially concentrated and washed with a saturated $\mathrm{NaHCO}_{3}$ aqueous solution. The organic solvent was further evaporated to obtain an orange oil.

The orange oil was carefully purified by flash chromatography (column: diameter: $8 \mathrm{~cm}$, length: $34 \mathrm{~cm}$; crude oil dissolved in EtOAc, elution with EtOAc:MeOH:NH${ }_{4} \mathrm{OH}$ 28.0-30.0 \% aq 28:3:1) to obtain the diamino ester as diastereomeric mixture $\mathbf{3 a}+\mathbf{3 b}$ (diastereomeric ratio 85:15). The yellow oil solidifies upon freezing (15.16 g, $35.04 \mathrm{mmol}, 86 \%$ ). 
$\mathrm{Rf}=0.27$ (EtOAc:MeOH:NH${ }_{4} \mathrm{OH} 28.0-30.0 \%$ aq 9:1:1; chloranil); ${ }^{1} \mathrm{H} \mathrm{NMR}\left(500 \mathrm{MHz}, \mathrm{CDCl}_{3}\right.$, only indicative peaks are listed) $\delta 4.01\left(\mathrm{t}, 6.5 \mathrm{~Hz}, 2 \mathrm{H}\right.$, ester $\left.\mathrm{O}-\mathrm{CH}_{2}\right), 3.17$ (br. s, $1 \mathrm{H}, 12 \beta \mathrm{H}$ ), 2.73 (br. s, 1 H, $3 \beta \mathrm{H}$ ), 2.31-2.40 (m, $2 \mathrm{H}$ ), 2.18-2.26 (m, $2 \mathrm{H}), 2.02$ (s, $2 \mathrm{H}$ ), 0.99-1.94 (series of $\mathrm{m}), 0.88-0.99(\mathrm{~m}, 12 \mathrm{H}), 0.71(\mathrm{~s}, 3 \mathrm{H})$; IR (neat): $v_{\max }=3382(\mathrm{~m}), 3321(\mathrm{~m}), 3188(\mathrm{~m}, \mathrm{br}), 1732$ (s); ESI-MS: $m / z$ (\% rel. int.) $=433.0$ (100) $[\mathrm{M}+\mathrm{H}]^{+}$; HR-MS (ESI) $\mathrm{m} / \mathrm{z}$ calcd. for $\mathrm{C}_{27} \mathrm{H}_{48} \mathrm{~N}_{2} \mathrm{O}_{2}$ $+\mathrm{H} 433.3789$, found 433.3783 .

Preparation of $n$-propyl $3 \alpha$-(allyloxycarbonylamino),12 $\alpha$-amino-5 $\beta$-cholan-24-oate (4a). The diastereomeric mixture 3a $+3 \mathbf{b}(5.07 \mathrm{~g}, 11.71 \mathrm{mmol})$ was dissolved in $\mathrm{CHCl}_{3}(500 \mathrm{~mL})$ and dry $\mathrm{Et}_{3} \mathrm{~N}$ (3.4 mL, $24.39 \mathrm{mmol}, 2.1 \mathrm{eq}$ ) was added. The yellow solution was stirred at room temperature, Alloc $2 \mathrm{O}(1.75 \mathrm{~mL}, 10.54 \mathrm{mmol}, 0.9 \mathrm{eq})$ was added in one portion and the mixture was reacted overnight. After TLC showed completeness of reaction (EtOAc:MeOH: $\mathrm{NH}_{4} \mathrm{OH}$ 28.0-30.0\% aq 9:1:1 and $\mathrm{CH}_{2} \mathrm{Cl}_{2}: \mathrm{MeOH} 9: 1$; chloranil and ninhydrin), the mixture was transferred to a separation funnel and a saturated $\mathrm{NaHCO}_{3}$ aqueous solution $(300 \mathrm{~mL})$ was added. The phases were separated and the aqueous phase was extracted with $\mathrm{CHCl}_{3}(300 \mathrm{~mL})$. The combined organic phases were partially concentrated under reduced pressure and washed with a new portion of a saturated $\mathrm{NaHCO}_{3}$ aqueous solution. The organic phase was concentrated under reduced pressure to obtain a viscous yellow oil. The oil was carefully purified by flash chromatography (column: diameter: $4.5 \mathrm{~cm}$, length: $32 \mathrm{~cm}$; crude oil dissolved in $\mathrm{CH}_{2} \mathrm{Cl}_{2}$, elution with $\mathrm{CH}_{2} \mathrm{Cl}_{2}: \mathrm{MeOH} 98: 2$ ) to obtain diastereomerically pure 4a as a yellow oil (2.80 g, $5.42 \mathrm{mmol}, 46 \%)$.

$[\alpha]_{\mathrm{D}}=+96.7(c=0.770, \mathrm{EtOH}) ; \mathrm{Rf}=0.66\left(\mathrm{CH}_{2} \mathrm{Cl}_{2}: \mathrm{MeOH} 9: 1 ;\right.$ ninhydrin $) ;{ }^{1} \mathrm{H} \mathrm{NMR}(500 \mathrm{MHz}$, $\left.\mathrm{CDCl}_{3}\right) \delta 5.86-5.97(\mathrm{~m}, 1 \mathrm{H}$, Alloc), 5.29 (dd, $1.6 \mathrm{~Hz} ; 17.3 \mathrm{~Hz}, 1 \mathrm{H}$, Alloc), 5.20 (dd, $1.3 \mathrm{~Hz}$; $10.4 \mathrm{~Hz}, 1 \mathrm{H}$, Alloc), 4.59 (d, $6.7 \mathrm{~Hz}, 1 \mathrm{H}, \mathrm{NH}), 4.54$ (d, 4.4 Hz, $2 \mathrm{H}$, Alloc), 4.02 (t, $6.7 \mathrm{~Hz}, 2 \mathrm{H}$, ester $\mathrm{O}-\mathrm{CH}_{2}$ ), 3.49 (br. s, $1 \mathrm{H}, 3 \beta \mathrm{H}$ ), 3.17 (br. s, $\left.1 \mathrm{H}, 12 \beta \mathrm{H}\right), 2.32-2.40$ (m, $\left.1 \mathrm{H}\right), 2.18-2.27$ (m, $1 \mathrm{H}), 0.99-1.91$ (series of $\mathrm{m}, 26 \mathrm{H}), 0.90-0.99(\mathrm{~m}, 9 \mathrm{H}), 0.71(\mathrm{~s}, 3 \mathrm{H}) ;{ }^{13} \mathrm{C} \mathrm{NMR}(125 \mathrm{MHz}$, $\left.\mathrm{CDCl}_{3}\right) \delta 174.2$ (COOR), $155.4($ Alloc $\mathrm{C}=\mathrm{O}), 133.0\left(\right.$ Alloc $\left.\mathrm{CH}=\mathrm{CH}_{2}\right) 117.3\left(\right.$ Alloc $\left.\mathrm{CH}=\mathrm{CH}_{2}\right)$, 65.8 (ester $\left.\mathrm{O}-\mathrm{CH}_{2}\right), 65.1\left(\right.$ Alloc $\left.\mathrm{O}-\mathrm{CH}_{2}\right), 54.0(\mathrm{CH}), 50.9(\mathrm{CH}), 47.9(\mathrm{CH}), 47.8(\mathrm{CH}), 46.1(\mathrm{C})$, $42.3(\mathrm{CH}), 36.2(\mathrm{CH}), 35.6\left(\mathrm{CH}_{2}\right), 35.1(\mathrm{CH}), 34.0(\mathrm{C}), 33.8\left(\mathrm{CH}_{2}\right), 33.5(\mathrm{CH}), 31.3\left(\mathrm{CH}_{2}\right), 30.9$ $\left(\mathrm{CH}_{2}\right), 28.7\left(\mathrm{CH}_{2}\right), 28.1\left(\mathrm{CH}_{2}\right), 27.6\left(\mathrm{CH}_{2}\right), 26.9\left(\mathrm{CH}_{2}\right), 26.0\left(\mathrm{CH}_{2}\right), 23.7\left(\mathrm{CH}_{2}\right), 23.2\left(19-\mathrm{CH}_{3}\right)$, $21.9\left(\right.$ ester $\left.\mathrm{CH}_{2}\right), 17.1\left(21-\mathrm{CH}_{3}\right), 13.7\left(18-\mathrm{CH}_{3}\right), 10.3\left(\right.$ ester $\left.\mathrm{CH}_{3}\right)$; IR (neat): $v_{\text {max }}=3336(\mathrm{w})$, 1724 (s); ESI-MS: m/z (\% rel. int.) $=517.5$ (100) $[\mathrm{M}+\mathrm{H}]^{+}$; HR-MS (ESI): $\mathrm{m} / \mathrm{z}$ calcd. for $\mathrm{C}_{31} \mathrm{H}_{52} \mathrm{~N}_{2} \mathrm{O}_{4}+\mathrm{H}$ 517.4000, found 517.4020.

Verification experiment (conversion of 4a to 3a). 4a (95.8 $\mathrm{mg}, 0.185 \mathrm{mmol})$ was dissolved in dry THF $(1.9 \mathrm{~mL})$ and the reaction mixture was stirred at room temperature under argon. $\mathrm{Pd}\left(\mathrm{PPh}_{3}\right)_{4}(4.5 \mathrm{mg}, 0.0039 \mathrm{mmol}, 0.02 \mathrm{eq})$ was added and the bright yellow solution was stirred for 5 minutes, followed by the addition of $\mathrm{NaBH}_{4}(14.4 \mathrm{mg}, 0.38 \mathrm{mmol}, 2.1 \mathrm{eq})$. The mixture was stirred overnight at room temperature. ${ }^{12}$

After TLC check $\left(\mathrm{CH}_{2} \mathrm{Cl}_{2}: \mathrm{MeOH}\right.$ 9:1 and EtOAc:MeOH: $\mathrm{NH}_{4} \mathrm{OH}$ 28.0-30.0 \% aq 9:1:1; ninhydrin and PMA) the reaction was quenched with a $1 \mathrm{M} \mathrm{HCl}$ aqueous solution (15 $\mathrm{mL})$ and the mixture was transferred to a separation funnel. The mixture was made basic with a saturated 
$\mathrm{NaHCO}_{3}$ aqueous solution $(40 \mathrm{~mL})$ and the product was extracted in $\mathrm{CH}_{2} \mathrm{Cl}_{2}$. The organic phase was dried on $\mathrm{K}_{2} \mathrm{CO}_{3}$, filtered and concentrated under reduced pressure.

The brownish oil was purified by flash chromatography (EtOAc:MeOH:NH $4 \mathrm{OH} 28.0-30.0 \%$ aq 28:3:1). Although the product looked pure on TLC (EtOAc: $\mathrm{MeOH}: \mathrm{NH}_{4} \mathrm{OH} 28.0-30.0 \%$ aq 9:1:1; chloranil or PMA), no clear NMR spectra could be obtained.

Therefore a solid phase extraction was performed: $\sim 20 \mathrm{mg}$ of the product was dissolved in $\mathrm{MeOH}(2 \mathrm{~mL})$ and transferred into a solid phase reactor. Amberlyst 15 (wet) acidic ion-exchange resin $(105.6 \mathrm{mg})$ was added and the mixture was shaken for 30 minutes. The resin was filtered and washed with $\mathrm{CH}_{2} \mathrm{Cl}_{2}$, EtOAc and $\mathrm{MeOH}$. A $7 \mathrm{M} \mathrm{NH}_{3}$ solution in $\mathrm{MeOH}(2 \mathrm{~mL})$ was added and the reaction mixture was shaken manually, filtered and washed with $\mathrm{MeOH}$. The filtrate was evaporated and dried under high vacuum to obtain $8 \mathrm{mg}$ of diastereomerically pure 3a as a colourless oil, which proved pure enough by NMR.

\section{Alloc deprotection on solid support (conversion of 5 to 6)}

Deprotection with $\mathrm{Pd}\left(\mathrm{PPh}_{3}\right)_{4} / \mathrm{Bu}_{3} \mathrm{SnH} /$ morpholine. Resin-bound construct 5 (30.1 mg, 0.11 $\mathrm{mmol} / \mathrm{g}, 0.0033 \mathrm{mmol})$ was weighed into a $5 \mathrm{ml}$ plastic syringe and swollen in dry $\mathrm{CH}_{2} \mathrm{Cl}_{2}(500$ $\mu \mathrm{l})$ for 10 minutes under argon. Morpholine $(109 \mu \mathrm{l}, 1.24 \mathrm{mmol}, 376 \mathrm{eq})$ and $\mathrm{Bu}_{3} \mathrm{SnH}(37 \mu \mathrm{l}$, $0.14 \mathrm{mmol}, 42 \mathrm{eq})$ were added, followed by $\mathrm{Pd}\left(\mathrm{PPh}_{3}\right)_{4}(1.6 \mathrm{mg}, 0.0014 \mathrm{mmol}, 0.4 \mathrm{eq})$ and the reactor was flushed with argon. The mixture was agitated for $22 \mathrm{~h}$ at room temperature, shielded from light.

The resin was filtered and washed with $\mathrm{N}$, N-dimethylformamide, $\mathrm{MeOH}$ and $\mathrm{CH}_{2} \mathrm{Cl}_{2}$. An analytical sample $(\sim 1 \mathrm{mg})$ was suspended in $\mathrm{CH}_{3} \mathrm{CN}$ and irradiated with UV light (365 nm) for 3 h.

When analysis showed incomplete deprotection, the reaction was repeated. Since we still observed incomplete deprotection, we decided to test a different protocol:

Deprotection with $\mathrm{Pd}\left(\mathrm{PPh}_{3}\right)_{4}$ /anilinium p-toluenesulfinate. ${ }^{9 b, 10}$ The resin was swollen in $\mathrm{N}$ methylpyrrolidinone $(204 \mu \mathrm{l})$ under argon for 15 minutes. The resin was filtered and anilinium $p$ toluenesulfinate $(32.5 \mathrm{mg}, 0.14 \mathrm{mmol}, 42 \mathrm{eq})$ was added. The mixture was made homogenic by addition of $\mathrm{N}$-methylpyrrolidinone $(170 \mu \mathrm{l})$ and $\mathrm{Pd}\left(\mathrm{PPh}_{3}\right)_{4}(1.1 \mathrm{mg}, 0.0001 \mathrm{mmol}, 0.03 \mathrm{eq})$ was added. An additional $30 \mathrm{ml} \mathrm{N}$-methylpyrrolidinone was added. The mixture was flushed with argon and shaken for 2 hours at room temperature, shielded from light.

The resin was filtered and washed with dry N,N-dimethylformamide, $\mathrm{MeOH}$ and $\mathrm{CH}_{2} \mathrm{Cl}_{2}$. Similar to the previous reaction a small sample was cleaved photolytically from the resin and analyzed as described.

\section{Acknowledgements}

This work was financially supported by Ghent University (BOF 011D16403) and the FWO Vlaanderen (KAN 1.5.186.03; G.0347.04N). We gratefully thank A. P. Davis and C. J. Burrows for useful discussions. 


\section{References}

1. Verzele, D.; Madder, A. Eur. J. Org. Chem. 2007, doi: 10.1002/ejoc.200600972.

2. (a) Cheng, Y. A.; Suenaga, T.; Still, W. C. J. Am. Chem. Soc. 1996, 118, 1813. (b) Barry, J. F.; Davis, A. P.; Pérez-Payán, M. N.; Elsegood, M. R. J.; Jackson, R. F. W.; Gennari, C.; Piarulli, U.; Gude, M. Tetrahedron Lett. 1999, 40, 2849. (c) Zhou, X.; Rehman, A.; Li, C.; Savage, P. B. Org. Lett. 2000, 2, 3015. (d) del Amo, V.; Siracusa, L.; Markidis, T.; Baragaña, B.; Bhattarai, K. M.; Galobardes, M.; Naredo, G.; Pérez-Payán, M. N.; Davis, A. P. Org. Biomol. Chem. 2004, 2, 3320. For various applications and use of steroid scaffolds, see also: (e) Salunke, D. B.; Hazra, B. G.; Pore, V. S. ARKIVOC 2003, (ix), 115. (f) Maltais, R.; Tremblay, M. R.; Ciobanu, L. C.; Poirier, D. J. Comb. Chem. 2004, 6, 443. (g) Davis, A. P. Coord. Chem. Rev. 2006, 250, 2939. (h) Bortolini, O.; Fantin, G.; Fogagnolo, M.; Maietti, S. ARKIVOC 2006, (vi), 40. (i) Salunke, D. B.; Hazra, B. G.; Pore, V. S. Curr. Med. Chem. 2006, 13, 813.

3. (a) Gao, H. W.; Dias, J. R. Org. Prep. Proc. Int. 1999, 31, 145. (b) Virtanen, E.; Kolehmainen, E. Eur. J. Org. Chem. 2004, 16, 3385.

4. Hsieh, H.; Muller, J. G.; Burrows, C. J. Bioorg. Med. Chem. 1995, 3, 823.

5. (a) Broderick, S.; Davis, A. P.; Williams, R. P. Tetrahedron Lett. 1998, 39, 6083. (b) Li, C.; Rehman, A.; Dalley, N. K.; Savage, P. B. Tetrahedron Lett. 1999, 40, 1861. (c) Davis, A. P.; Pérez-Payán, M. N. Synlett 1999, 991. (d) del Amo, V.; Bhattarai, K.; Nissinen, M.; Rissanen, K.; Pérez-Payán, M. N.; Davis, A. P. Synlett 2005, 8, 1319.

6. (a) Kocieński, P. J. Protecting Groups; Thieme: Stuttgart; New York, 1994; pp. 199-201. (b) For reviews regarding allyl based protecting groups, see: Guibé, F. Tetrahedron 1997, 53, 13509 and 1998, 54, 2967.

7. (a) Holmes, C. P.; Jones, D. G. J. Org. Chem. 1995, 60, 2318. (b) Holmes, C. P. J. Org. Chem. 1997, 62, 2370.

8. (a) Vanhoenacker, G.; Li, L.; Lynen, F.; Madder, A.; De Clercq, P.; Sandra, P. J. Sep. Sci. 2002, 25, 671. (b) Madder, A.; Li, L.; De Muynck, H.; Farcy, N.; Van Haver, D.; Fant, F.; Vanhoenacker, G.; Sandra, P.; Davis, A. P.; De Clercq, P. J. J. Comb. Chem. 2002, 4, 552.

9. (a) Fernández-Forner, D.; Casals, G.; Navarro, E.; Ryder, H.; Albericio, F. Tetrahedron Lett. 2001, 42, 4471. (b) Opatz, T.; Liskamp, M. J. Org. Lett. 2001, 3, 3499.

10. (a) Honda, M.; Morita, H.; Nagakura, I. J. Org. Chem. 1997, 62, 8932. (b) Chamorro, C.; Hofman, J.; Liskamp, R. M. J. Tetrahedron 2004, 60, 8691.

11. Dias, J. R.; Gao, H.; Kolehmainen, E. Spectrochim. Acta A 2000, $56,53$.

12. (a) Beugelmans, R.; Bourdet, S.; Bigot, A.; Zhu, J. Tetrahedron Lett. 1994, 35, 4349. (b) Beugelmans, R.; Neuville, L.; Bois-Choussy, M.; Chastanet, J.; Zhu, J. Tetrahedron Lett. 1995, 36, 3129. 